\title{
On Men and Objects: Staging the Divided Subjectivity of Displacement in zero degrees
}

Yana Meerzon

In contemporary theatre, objects often appear in the functions of subjects, both in the performances based on realist aesthetics and in more stylized or abstract works, in which subjects and objects are used interchangeably. Despite their inanimate nature, on stage objects can acquire an action force (VELTRUSKÝ 1990:88). They can be manipulated by live performers or perceived by the audience as acting on their own, i.e. exhibiting the will for action. The most noticeable example of this phenomenon is théâtre d'objects, which emerged in the 1980s. It employs animation of everyday objects to construct "material images of humans, animals, or spirits that are created, displayed, or manipulated in narrative or dramatic performance" (PROSCHAN 1983: 4). This view of the theatrical animation of an object links its on-stage work to puppetry, in which the agency of the inanimate matter is put forward, examined, and defended. Material performance, Dassia Posner argues, is "performance that assumes that inanimate matter contains agency not simply to mimic or mirror, but also to shape and create" (POSNER 2015: 5). What interests me here is the scale of subject (actor)/object (puppet) interdependency, which is mobilized on stage not in the forms of a traditional puppet theatre or even théâtre d'objects, but in the hybrid stylistics of tanztheater (dance theatre). The 2005 dance-duet zero degrees created and performed by Sidi Larbi Cherkaoui, a Moroccan-Flemish choreographer, and Akram Khan, a Bangladeshi born UK dancer, is one such example. Using the language of contemporary dance, storytelling, dramatic narration and the two life-size dummies in the functions of objects and subjects of action, zero degrees demonstrates how a theatre object can acquire agency on stage. Zero degrees, I argue, challenges a traditional view of dance as presence of "authentic human bod[ies]" (WAGNER 2006: 126). Using dancers' bodies and dummies (the replicas of the performers' bodies) interchangeably, when dummies (the objects) turn into dancers (the subjects), zero degrees presents a special case of theatrical intermediality. When the dummies join the 
dancers on stage, the dancers begin to act as objects, manipulated by these life-size puppets. In zero degrees, in other words, the inanimate matter (a large scale puppet) becomes a hypermedium of theatrical action and "assume[s] live quality of the theatrical body" (WAGNER 2006: 127). Focusing on the spectator's work as a recipient of this subject/object interdependency, this performance invites following questions: "Is the puppet a live performing body, present, perceptible, and sensitive like the body of the actor? Is it an object body, a body image, or a medial representation of the human body? Or is it a combination of any or all of the above?" (WAGNER 2006: 127).

In this article I offer a tentative response to these questions: in the hybridity of its theatrical expression, I demonstrate, zero degrees relies on the performative gestures of mirroring and estrangement. It stages a performer's body as an object of presence (PHELAN 1993) and as a construct of embodied interculturalism (MITRA 2015); but also as an act of personification (VELTRUSKÝ 1983). A performative gesture of making an object anthropomorphized, personification joins two levels of actions produced by a human being: the actions "governed by habit" and our proper actions that "deriv[e] from the unlimited initiative of the subject" (VELTRUSKÝ 1983:88), and so it makes the inanimate matter come to life. In zero degrees, the two dummies appear as the objects of the performers' manipulation and as the subjects of action, independent in their own will from the work or intentions of the dancers. By making this interdependency of bodies and objects visible, zero degrees stages the body of the performer as a mediated entity, separate from the performer's self. To discuss this actor/puppet tension, which emerges on stage as "interpenetrated" so "no exact limit can be drawn between them" (VELTRUSKÝ 1990:86), I will now provide a brief analysis of its semiotic interdependency. As my theoretical lens, I use the Prague School's theater aesthetics, and pay homage to the work of Jiří Veltruský.

\section{Jiří Veltruský - on body and object of presence}

Jiří Veltruský theorizes theatre acting as "the representation of human and anthropomorphic beings [...] and their actions and behavior by human beings" (VELTRUSKÝ 1983: 70). At its core, acting is the process of creating a stage figure and its actions. This process reflects the twofold nature of a dramatic character - a "human or anthropomorphic bein[g]" who comes on stage as a sum of their own "actions and behavior" (VELTRUSKÝ 1983: 70). Creating a dramatic character consists of the actor's "breaking down and building up of human looks and behavior" and "eliminating some components, modifying others, adding new ones, reorganizing their mutual relations" (VELTRUSKÝ 1983: 80). In contemporary theatre, often there is no separation between actor and character; hence the semiotic materiality of a performer's body becomes the focus of artistic investigation. An autobiographical dance-performance, such as zero degrees, stages the performer's body and the character's body as collapsing into each other, with the presence of another body or an object - a dummy, in this case - suggesting a doubling and mirroring effect of con- 
temporary consciousness. It also invites theoretical questions of the actor/puppet or the subject/object interconnection.

To Veltruský, the work and significance of theatre objects must be always examined in direct relation to the actor's actions, which he positions on the scale from personification to intended actions (VELTRUSKÝ 1990: 89) and as metonymy. In his 1940 article, "Man and Object in Theater", Veltruský argues that in a theatre performance an acting subject should be defined not by inherent spontaneity or liveness, but by an actor's ability to initiate action (VELTRUSKÝ 1990: 83). To Veltruský, "the actor centers all the meanings upon himself," and through their actions, the actor "replace[s] all the sign carriers" (VELTRUSKÝ 1990: 84); whereas all components of the actor's presence on stage - from materiality of the body to one's make up and costume - are the signs to be attributed to the character (VELTRUSKÝ 1990: 85).

Speaking of dramatic character, Veltruský differentiates between characters as subjects defined by a developed set of psychological and emotional characteristics and characters as supporting figures, whose characteristics and actions are schematic, limited by their subordinate dramatic functions. The actions of these figures are stereotypical and repetitive; so on stage these figures serve as human props not "active performers" (VELTRUSKÝ 1990: 86). When the character's actions fall to zero level, the actor turns into an object. "People in these roles can be replaced by lifeless dummies," Veltruský writes; they can function as parts of the stage set and signify a transition "between the sphere of the man and the sphere of the object" (VELTRUSKÝ 1990: 86). Veltruský proposes to study this subject/object interdependency looking at a multidirectional vector of change: actors as agents of action turning into objects and objects as non-agents of action turning into subjects. He argues: when there are no subjects (live actors) on stage, objects can turn into them and so become the subjects of action. In this situation, "the action force of the object comes to fore in all its power. [...] Without any intervention of the actor, the props shape the action. They are no longer the tools of the actor, we perceive them as spontaneous subjects, equivalent of the figure of the actor" (VELTRUSKÝ 1990: 88).

As props, objects can be "signified - by human beings and their actions and behavior. They can be physically present or represented on the stage by other objects [...]. But they may also be evoked by acting alone. In any event, their precise dramatic meaning derives from the way they are related to the stage figure and stage action" (VELTRUSKÝ 1983: 85). When objects become signs, "their capacity to evoke such actions as part of their own respective meanings tends to become their chief quality" (VELTRUSKÝ 1983: 87). As puppets, objects can turn into "machines stimulating life" (VELTRUSKÝ 1983: 107); so in puppet theatre, a puppeteer "generates the tendency to perceive the puppet, an inanimate object, as a live anthropomorphic being and the movements and speeches produced by the puppeteer's manipulation and delivery as that being's own activities" (VELTRUSKÝ 1983: 106). This puppet/puppeteer interdependency leads to the process of vivification; and it indicates the actor/puppeteer's desire to fill the object/puppet with life (VELTRUSKÝ 1983: 88). Often vivification emerges as theatrical metonymy: it takes place when the puppet comes live on stage, when the actor 
"produces [their] vivifying effect on the puppets," and when the puppet/puppeteer relation is "inverted in the sense that the live performer represents the undergoer of the action performed by the puppet" (VELTRUSKÝ 1983: 117).

zero degrees widely capitalizes on these tensions: it presents the subject/object interdependency unfolding across two differently pointed vectors of action - when a dancer's stage action falls to a zero degree, he turns into an object of manipulation by his own puppet; whereas, as a result of vivification, a dummy becomes the agent of action and emerges as the subject of a performative narration.

\section{zero degrees of embodied interculturalism}

A story of exilic point of no-return, zero degrees investigates construction of masculinity, brotherhood, and shattered identities of displacement. It features Akram Khan, a Bangladeshi born UK citizen, as the protagonist of the narrative of homecoming, on his "first visit to India" (COOLS 2015: 190). This story begins with Akram on the train to Bangladesh and unfolds in "the straightforward chronology of a real journey with a clear beginning - the crossing of the border and the entering of the country" (COOLS 2015: 188), and Akram's "projected arrival in Calcutta" (COOLS 2015: 188). It helps "questioning his identity as a second-generation immigrant, growing up inbetween cultures, in-between bodies" (COOLS 2015: 190).

Sidi Larbi Cherkaoui is Akram's partner in this journey: a co-creator of zero degrees' dramaturgical narrative and choreography, he also takes on many functions and characters. Most of the time, however, Sidi Larbi's on-stage presence serves as Akram's alter-ego, in which Akram's voyage of discovery and acceptance is reflected. At the same time, zero degrees acts as Cherkaoui's personal artistic project: it helps Sidi Larbi tell his own story of difference, using "the stories of others" (COOLS 2015: 184). A son to a Flemish mother and Moroccan father, "Sidi Larbi Cherkaoui grew up in Antwerp and attended Koran school until the age of twelve. Being of mixed origin, Cherkaoui has always found it difficult to fully identify with a single culture" (UYTTERHOEVEN 2009: 8 ); so, his choreography reflects the artist's belief in "consistency of transformation" (UYTTERHOEVEN 2014: 255). "Interested in dance and movement as cross-religious expressions of a more universal spirituality" (SORGEL 2015: 169), Cherkaoui's choreography is based on the method to "give and take that entails an ethics of change" (SORGEL 2015: 169). Encountering his work, Cherkaoui believes, will help spectators "emerge as richer beings"; thus, he aims to "bring people into contact with each other" (UYTTERHOEVEN 2014: 257). His philosophy revolves around the notions of completeness, circularity, and reconciliation; so in his theatre, bodies, objects, puppets, space, sound and words constitute continuous performative material and semio/ spheres. This search for continuity and wholeness suggests Cherkaoui's longing for different cultures; it clearly marks the artistic and philosophical quest of zero degrees.

Dirven by the autobiographical experiences of Akram Khan, this story of homecoming is also filled with strangers. One of them is an unfriendly police officer 
(played by Sidi Larbi), who Akram meets at the border-control. Only by miracle he does not confiscate Akram's UK passport, his license for freedom of movement. Another set of strangers, who Akram meets, is an old Indian couple. When an old man suddenly dies, Akram offers his help to the man's widow to move the body. He suddenly realizes, however, that he should not touch it, because, as a foreigner, he might be accused of murder. The old woman is left alone to deal with the body; whose deadness is forever imprinted on Akram's memory and imagination, and onto his audience's.

Despite the highly populated nature of zero degrees, on stage there are only two dancers, joined later by two dummies; so the effect of doubling and mirroring is at the basis of this tale's theatrical language. A form of dialogue, zero degrees is based on an exchange of opinions and also acts as an attempt at self-clarification. In its narrative structures, it intersects movement with text spoken by two dancers in unison. Texts help "rhythmically organize the material" (COOLS 2015: 188); they serve as dance "punctuation that marks the beginning and end of different movement sections in such a way that they both stay separated and are connected" (COOLS 2015: 188). A spatial/ figural form, zero degrees also uses "visceral sensuality and corporeal experience" (BOENISCH 2013: 114). When it comes to dialoguing with bodies and objects, zero degrees utilizes repetition with a difference. It presents performers' movements as syncopated, looking similar but never the same, repeating each other but never identically, so the juxtaposition of the text, the bodies and the movement creates visual and emotional tension. The unison narration used in zero degrees functions as an outline of actions and events that drive the story forward; but when the dancers manipulate dummies, their language becomes non-verbal - their movements and gestures assume narrative function, almost to the degree of being illustrative of the dialogue.

Designed by Antony Gormley, a UK sculptor and architect, the setting of zero degrees further re-enforces this sense of doubling and mirroring. The action unfolds in the empty space of a white-washed stage surrounded by transparent walls. Behind the central wall, there are several musicians. Their invisible presence suggests the power of Gods watching over the characters and holding the threads of their actions and fate in their mighty hands. The musicians' presence, however, is revealed only in the moments of the characters' spiritual change. Thus, the spatial dramaturgy of this performance invites contemplation on "the vulnerability of the human body" (SORGEL 2015: 171); it lures the dancers into exploring stillness and movement as essential components of subject/object and life/death interdependency.

Two dummies, also designed by Gormley, re-enforce and re-enact the performers' presence in this empty and enigmatic space. The dummies are the iconic replicas of each of the dancers' bodies; so the actors "perform both as themselves and as the actual personages they represent" (MARTIN 2006: 10). The dummies' presence intensifies the device of mirroring and repetition: it creates an effect of a theatrical encounter in body, which refers to a continuous loop of cultural, logical, ethic and aesthetic recognitions and adjustments that take place within the body of a performer and between the stage and the audience. The dancers interact with each other and manipulate the dummies. 
At times the action gets violent and intimate at the same time, it creates both the comic effect and the effect of the uncanny.

Watching Khan and Cherkaoui interacting with each other through dummies reveals the mechanisms of co-presence common in a puppet theater. Co-presence "establishes a relation of self to Other between two beings that are ontologically different" (PIRIS 2015: 30). It explains the ontological difference between animate and inanimate matter:

Co-presence "supposes that the performer creates a character through the puppet but also appears as another character whose presence next to the puppet has a dramaturgical meaning. [...] co-presence requires the hybridization of the two forms of body schema [...] in acting; the actors' aim is to focus the audience's attention on their body, whereas the puppeteer's aim is to focus the audience's attention on the puppets. The co-presence of the puppeteer and the puppet requires that a double focus on both the performer and the puppeteer is achieved." (PIRIS 2015: 31)

In this act of co-presence, the body of a puppeteer is mediated through puppet; hence the subjectivity of a living body is projected onto the materiality of the object, which becomes animated in the act of playing. In zero degrees, this ontological difference is thematically concretized through the story of displacement and return. This way, it acquires an ideological status and political weight. Dedicated to staging subjectivity of a migratory subject in movement, zero degrees constructs and mediates it using dancing bodies and objects on stage. To externalize this divided subjectivity of migration within the time/space of its dramaturgical and performative compositions, zero degrees uses the device of interweaving of cultures, called to "creat[e] an innovative performance aesthetic, which establishes and gives shape to new collaborative policies in society. It probes the emergence, stabilization, and de-stabilization of cultural identity. Here, the aesthetic and the political merge" (FISCHER-LICHTE 2009: 400). In zero degrees, in other words, interweaving of bodies, cultures and performance techniques probes the leading questions of contemporary world, expressed through the interaction of animate (bodies) and in-animate (dummies) matter.

The performance ends with the ritual of lament. To mourn the death of the old Indian man, Sidi Larbi Cherkaoui puts a lifeless dummy onto his lap and sings a Hebrew song, Jerusalem of gold, copper and light. The song serves as the artist's personal entry point into the story of Akram's homecoming (COOLS 2015: 184). "Half Arabic," Cherkaoui uses this Hebrew song as his way to "reach out to the other". The song "relate[s] to the difficult relationship with his dead father, and it support[s] [...] his beliefs in a non-hierarchical coexistence of culture and traditions" (COOLS 2015: 185). This moment presents the highest emotional tension in the production; and it also mobilizes "a processual and embodied aesthetics that is generated from [the artist's] own lived, othered realities with multiple affiliations to cultures, people, nations, performance traditions and histories" (MITRA 2015: 27).

zero degrees, in other words, uses the languages of theater, dance and puppetry to artistically investigate how through the mechanisms of performance and in its tenden- 
cies for intermediality the construction of a divided self can be externalized. In its title, it refers to an 'in between' point, the point between positive and negative, between water and ice, between life and death, between one state boundary and the other, between performance and visual arts" (UYTTERHOEVEN 2009: 11). A play between people and objects, zero degrees turns into the reflection and extension of the performers' selves.

\section{Body: a mediated entity}

Preparing zero degrees, Akram Khan and Sidi Larbi Cherkaoui experimented with different levels of performance mediation and hybridity. They intertwined narrative forms of the Indian dance kathak as practiced by Akram Khan with the highly personalized language of contemporary dance - a "form of storytelling with the body" (COOLS 2016: 14) - as designed by Cherkaoui. Convinced that in today's world, an artist is "never just one thing, one character, one function" (CHERKAOUI in UYTTERHOEVEN 2009: 10); in Cherkaoui's theatre nothing - no body, no gesture, or word - appears on stage in its singularity. There is always a double, a repetition, a reenactment, a difference. To Cherkaoui "each of us has the ability to perform many different functions, within a project but also in life. By recognizing this multiplicity in oneself, you realise that 'the Other' $[\ldots]$ is often buried somewhere inside you too" (CHERKAOUI in UYTTERHOEVEN 2009: 10). "The Other", he strongly believes, is "never really detached from you", so on stage there is "a never-ending search for interconnectedness, for common roots" (CHERKAOUI in UYTTERHOEVEN 2009: 10). Cherkaoui's choreography often involves "copying and transforming one body into another" (UYTTERHOEVEN 2014: 251); a device which also allows the dancer to investigate the Other within oneself.

Dialogue is Cherkaoui's preferred method of on-stage composition and communication: it characterizes the dramaturgy of zero degrees as a dance-duet, based on different forms of conversation, such as an exchange of opinions, an attempt at self-clarification, and reconciliation. These interactions between people and objects activate what Veltruský calls the action force of a prop, which attracts, emanates, and provokes "the expectation of a certain action" (VELTRUSKÝ 1990: 88). zero degrees stages one body performed by another, multiplied through imitation and repetition, and seeking connection with itself via challenging the deadliness of a puppet. Thus, in its ethical focus on the questions of life/death interdependency, zero degrees capitalizes on the tension between animate and inanimate matter; and so it turns into a philosophical treatise expressed in movement, gesture, music, song and space. The dancers' work with the dummies serves as a device of storytelling, of sequencing and transition. It creates irony, strangeness, and comic relief: replicas of the dancers' bodies, in shape and weight, Gormley's puppets are "cut into elbows and shoulders and knees so they are only held together by a rope connector" (COOLS 2016: 277). When the dancers engage with them, not only do they bring these dummies to life, 
they also emphasize the "syntax" of the lifeless body that "isn't meaningless" (COOLS 2016: 277). Using the puppet of Khan, Cherkaoui creates a double of his partner. "By copying every hand gesture and every phrase of his story" (COOLS 2016: 278), he turns a very personal narrative of Khan's homecoming into "a universal one about our present state of multinational displacement” (COOLS 2016: 278). Brought to life through motion, the dummies became representations of each of performer's self as well as points of their difference:

Larbi and Akram had explored playing with the dummies in one of the earlier stages of the rehearsal process but the idea was never fully developed and eventually abandoned. It was only picked up again in the last week [of the rehearsals - YM] when we moved from the studio to the main stage. As is often the case in this critical moment, the performers literally felt momentarily lost in the vastness of the stage; which was highlighted this time by Gormley's design. They only had each other and their dummies, especially in the solo moments; as reference points to situate and center themselves on stage. Being life-size puppets, the dummies also allowed an "uncanny" treatment that the real bodies would not necessarily allow. (COOLS 2014: 189)

In the final version of the performance, not only these dummies promised playfulness, they provided "an emotional counterpoint to the lamentation in the second part of the piece” (COOLS 2014: 278).

Otakar Zich, the precursor of the Prague School theatre theory and Veltruskýs work in particular, made a clear distinction between the art of a live actor and that of a puppet. Zich "pointed out that of all the arts that represent human beings, only acting uses a material that conforms with the object, representing human beings by human beings, whereas in the puppet theater human beings are represented by puppets made of inanimate matter, as in sculpture; what differentiates the puppets from statues is that they are perceived as moving and speaking” (VELTRUSKÝ 1983: 89). To Zich, puppet, "an object made of inanimate matter" (VELTRUSKÝ 1983: 108), is similar to the actor; it can appear in its comic functions but also as uncanny. Marked by its "small size, the immobility of the face or body, and any awkwardness in the movements", puppet can present itself as "a live being"; whereas its inherited sense of the "uncanniness may turn into terror if the puppets are life-size, endowed with facial play, etc." (VELTRUSKÝ 1983: 108).

In zero degrees, dummies acquire both qualities - they serve in the functions of comic relief and as uncanny representations of deadliness of each dancing body. Theatrical manifestations of death turning into life, the phenomenon which marks each living body, dummies mobilize this philosophical paradox of theatrical action and reception. zero degrees illustrates that "in the puppet theater the differences between the stage figure and the stage action and their dynamic mutual relations are brought out but also confused" (VELTRUSKÝ 1983: 70). Brought to life through motion, dummies become doubles to each of the dancers; they also serve as points of their difference and accentuate the action force of each dancer. 
Both Akram and Sidi Larbi act as their puppets' masters or manipulators as well. "The manipulation of puppets is a human action" (VELTRUSKÝ 1983: 74), Veltruský writes; but it is not acting. In zero degrees, dancers act both as puppets and puppeteers. When they manipulate dummies, their own bodies become objects; whereas the dummies take on the functions of the active subjects. When a Sidi Larbi puppet slaps Akram's face, the action calls our attention to the liveness of the puppeteer, as the semiotic effect of the action is in "build[ing] up the represented characters and blur[ing] the difference between stage figure and character so as to creat[ing] an impression that the puppets are acting spontaneously" (VELTRUSKÝ 1983: 72). In this tension, "the performer's image may be twofold, relating to the puppet on the one hand and to the puppeteer on the other" (VELTRUSKÝ 1983: 105); so the work of a puppeteer approximates the actions of a painter or a sculptor, who "makes the picture or statue represent something rather than presenting it” (VELTRUSKÝ 1983: 74). In zero degrees, the dancers perform the efficacy of making a double, as by using a dummy to make a copy of oneself one "can look at the original in a new way" (COOLS 2016: 278). Not only these dummies promise playfulness, they provide "an emotional counterpoint to the lamentation" (COOLS 2016: 278).

At the same time, zero degrees capitalizes on the "dark feeling of uncertainty" (JENTSCH 2008: 224), which arises from our encounter with and recognition of the puppet's suggested liveness. It implies the ambiguity and the uncanny double, which carries in itself both the promise of Freudian fear and Bergsonian automization, which involves "the animation of objects" (BELL 2015: 43). zero degrees mobilizes the essence of puppet theatre as the art form inextricably linked to long-standing human desire "to play with the material world," i.e. "the animation of the dead world by living humans" (BELL 2015: 43). Using a dummy to enact "threatening, doubt-inciting, and anxiety-provoking events because [these objects] remind us that we are not necessarily in control" (BELL 2015: 50), zero degrees also engages with the anxieties of a modernist performance. As Bell writes:

\footnotetext{
Modernity has traditionally asserted its confidence in human potential, in our rational minds, in our ability to impose logic over untamed and illogical features of our world [...] but play with puppets, machines, projected images and other objects is constantly unsettling because it always leads to doubt about our mastery of the material world. [...] The essence of puppet, mask, and object performance $[. .$.$] is not mastery of the material world but a constant negotiation back$ and forth with it. Puppet performance reveals to us that the results of those negotiations are not at all preordained and that human superiority over the material world is not something to count on, especially since we all eventually end up as lifeless objects. (BELL 2015: 50)
}

Capitalizing on uncanny as juxtaposition between something familiar and something strange, zero degrees "pull[s] us back toward the old, sacred animist beliefs and in this way throw[s] doubt upon modern conceptions concerning the powers of reason and science," it turns the issue "back to us" (BELL 2015: 51). Manipulating two large puppets, the performers construct a complex network of co-presence(s) on stage. Khan 
and Cherkaoui multiply their on-stage presence by making the movement of their bodies dependent on the presence or rather the will of the puppets; so their bodies constantly undergo the process of puppetization (PIRIS 2015: 35). This way, the dancers' live presence achieves a hybridized ontology; their bodies become mediated, and thus allow the artists to reinforce one of the fundamental questions of contemporary world: "What is an identity and from where do we derive it?" (COOLS 2016: 278).

\section{Spectator: a corporeally involved receiver}

In zero degrees, Sidi Larbi Cherkaoui and Akram Khan's work with dummies is echoed in the work of the audience, at the level of our visceral associations and projections. It unfolds similarly to how Veltruský defines the audience's physical, emotional and sensorial engagement, when watching a puppet play:

The motions imparted to the puppets are similar to those of the beings they represent. [...] Because of their likeness to the movements of the represented beings (whether human or not), the puppets' motions convey a meaning of internal impulse corresponding to the impulse that produces the live beings' movements (automatic reflex, spontaneity, intention, etc.); and, by contiguity, this implied meaning reflects in the spectator's mind on the puppets themselves, thus tending to attribute to them life of their own. (VELTRUSKÝ 1983: 89)

Two-thirds in the performance, as he is approaching Calcutta, Akram's personal narrative ends as he must face a dead body for the first time in his life. From that moment on, zero degrees turns into a "lamentation for this dead body, repeated and performed in different styles and media; for instance, traditional adhinaya (the story element of kathak) performed by Khan, or a theatrical farce with 'dummies'" (COOLS 2015: 191). At the same time, while Sidi Larbi sings the Hebrew song, "holding his dummy pieta-like, Alkram dance[s] a distorted contemporary dance solo around his dummie soul, being both aura and ghost, leaving the body. The very last image of the piece [is] Larbi carrying Akram offstage, leaving the stage empty, except for the dummies with the cello and violin of the shadow world repeating their version of the lament theme" (COOLS 2015: 191). This last image re-enforces the presence of an intermedial force that defines zero degrees: it "mingle[s] puppet bodies with human actors [...], and so draw[s] a human body into an ambiguous position between an animated agent and an existential symbol of mediatization" (WAGNER 2006: 127). This dialectics of an intermedial force characterizes how the human body is mediated in this work: "the performers enter into the puppets bodies and humanize the animated objects - they interchange their human bodies with their object representations until the sharp line of division contradicts itself" (WAGNER 2006: 127). In other words, one can argue, in zero degrees "it is in the blurring of the border between the living and the dead, between live performance and mediated event that intermediality is located" (WAGNER 2005: 127). Intermediality serves here as "a matrix, which shapes and produces theatrical bodies 
through a negotiation between the discourse on the body, the spectator, and concepts of materiality" (WAGNER 2005: 128). A theatrical body - be it an actor, a dancer, or a puppet - "is not a given materiality but emerges as a result of performative acts" (WAGNER 2005: 128); so "the notion of a coherent live performing body becomes problematic. The problem [...] is generated by the material structure of puppetry, which admits and at the same time also marks the productive rupture of the hermetic body image" (WAGNER 2005: 128). This intermedial potential of puppet theater is reproduced in zero degrees as well: the audience is invited to practice their skills of intermedial reception by switching their theater reading gears to those used in dance and puppetry.

In puppet theatre, creating an analogy between an object and a human being is the primary task of a spectator, its consistency enables us "to construct the overall sense of the action for ourselves (VELTRUSKÝ 1983: 90); so the intermedial body/object tension holds on three components of building up and breaking down a puppet stage figure: such as consistency and audience reception (VELTRUSKÝ 1983: 90-101). In puppet theatre, Veltruský explains, breaking down and/or building up a stage figure of a puppet is made of "separating the visual components from delivery and language, either sequentially, by alternating speeches and physical actions, or simultaneously, by eliminating one of them [...] or by distributing them between different agents" (VELTRUSKÝ 1983: 99). A stage figure of a puppet presents "a particularly radical form of this separation" (VELTRUSKÝ 1983: 99), with its visual part "split between the puppets and the human beings" (VELTRUSKÝ 1983: 100). Its consistency presents a combination of "the inanimate object with motions carried out by means of that object and with human voice delivery" (VELTRUSKÝ 1983: 100), so "the inanimate objects, the motions, and the speeches [...] produce meanings that combine in different ways, and the meanings deriving from any one of them reflect on the other two" (VELTRUSKÝ 1983: 90). The consistency of the puppet stage figure is based on "heterogeneity of its components and the multifarious relations between them, including the subtle oscillation between what is inanimate and what is human" (VELTRUSKÝ 1983: 99). In puppet theatre, in other words, the work of the audience consists of noticing, decoding and putting together "the meanings produced by the many heterogeneous and spatially dispersed components into an integral sense of the performance" (VELTRUSKÝ 1983: 99).

This methodology of reception is somewhat similar to the one used in dance. Dance is "a movement in between a body-memory ('corps-memoire') and a body-being-present ('corps present'). By remembering ('rappel') their own body memory, the dancers reach out ('appel') to the audience. The open dramaturgy guarantees that the memories of the dancer trigger the memories of the spectator without them having or be identical or coincide" (COOLS 2015: 187). The open dramaturgy is effective as a method of the performance completion that can take place only when it meets its public. For the London audiences who came to see the opening of zero degrees on July 7, 2005, the day of the famous London tube massacre, this uncanny coincidence between the fictional events on stage and the tragic events in life re-enforced the symbolic meaning of the production. 
All through his carrier Sidi Larbi Cherkaoui's creations have had a remarkable and sometimes uncanny synchronicity with the events in the real world [...] but never was the "coincidence" so powerful as in the case of zero degrees. Two choreographers with a mixed identity between West European and Mutism cultures had created a lament for a dead body on a train, at exactly the same moment that fundamentalists created a massacre with many dead bodies on trains. (COOLS 2015: 191)

In this instance, zero degrees became an example of an intermedial performance that produces a new corporeally involved receiver (COOLS 2015: 128): someone who watches, listens and participates in its meaning-making not only through intellect but also somatically.

By introducing puppets into the multimodal artistic language of zero degrees, Sidi Larbi Cherkaoui and Akram Khan re-enforce its stylistics of dance theatre and convert the social-cultural questions of hybrid identities and divided self into ontological ones. With each dummy serving as an extension or a duplicate of a dancer's body, a new dichotomy of animated vs inanimate matter or real vs representational is brought into focus. So, in zero degrees, this cycle of inter-connections, reflections and duplications is re-enacted and mobilized. Through continuous interplay between and challenge of the subject/object - dancer/puppet interdependency, zero degrees re-enforces the intermedial nature of the object theatre; and it creates a new space for the divided self of a hypermodern individual to be artistically articulated, advocated, negotiated and recognized. It turns an experiment in theatrical aesthetics and ontology into an example of political and performative activism.

\section{Bibliography}

BELL, John. 2015. Playing with the eternal uncanny: the persistent life of lifeless objects. In Dassia N. Posner, Claudia Orenstein and John Bell (eds.). The Routledge Companion to puppetry and material performance. New York: Routledge, 2015: 43-53.

BOENISCH, Peter M. 2013. Spectres of subjectivity: on the fetish of identity in (post)postdramatic choreography. In Karen Jurs-Munby (ed.). Postdramatic theatre and the political. London: Bloomsbury, 2013: 111-129 .

COOLS, Guy. 2015. In-between dance cultures: on the migratory artistic identity of Sidi Larbi Cherkaoui and Akram Khan. Amsterdam: Valiz, 2015.

COOLS, Guy. 2016. "The Mythic Body". Sidi Larbi Cherkaoui. In Guy Cools and Lisa Marie Bowler (eds.). Imaginative bodies. Dialogues in performance practice. Amsterdam: Valiz, 2016: 21-41.

FISCHER-LICHTE, Erika. 2009. Interweaving cultures in performance: different states of being in-between. NTQ 25 (2009): 391-401.

JENTSCH, Ernst. 2008. Document: "On the Psychology of the Uncanny" (1906). In Jo Collins and J. Jervis (eds.). Uncanny modernity, cultural theories, modern anxieties.

Houndmills/Basingstoke/Hampshire/New York: Palgrave McMillan, 2008: 216-222. 
MARTIN, Carol. 2006. Bodies of evidence. The Drama Review 50 (2006): 8-15.

MITRA, Royona. 2015. Akram Khan: dancing new interculturalism. Houndmills/Basingstoke/ Hampshire/New York: Palgrave Macmillan, 2015.

PHELAN, Peggy. 1992. Unmarked: the politics of performance. London: Routledge, 1992.

PIRIS, Paul. 2015. Co-presence and ontological ambiguity of the puppet. In Dassia N. Posner, Claudia Orenstein and John Bell (eds.). The Routledge Companion to Puppetry and Material Performance. New York: Routledge, 2015: 30-42.

POSNER, Dassia N. 2015. "Material performance(s)." In Dassia N. Possner, Claudia Orenstein and John Bell. The Routledge Companion to Puppetry and Material Performance. London: Routledge, 2015: 5-7.

PROSCHAN, Frank. 1983. "The Semiotic Study of Puppets, Masks, and Performing Objects." Semiotica 47 (1983): 1-4: 3-44.

SORGEL, Sabine. 2015. Dance and the body in Western theatre, 1948 to the Present. London/New York: Palgrave Macmillan, 2015.

UYTTERHOEVEN, Lise. 2009. A cosmopolite's utopia: limitations to the generational Flemish dance history model. Platform 4 (Mapping Performance) (2009): 8-21.

UYTTERHOEVEN, Lise. 2014. On collaboration and navigating between dance cultures. An ethics of reconciliation. In Guy Cools and Pascal Gielen (eds.). The ethics of art: ecological turns in the performing arts. Amsterdam: Valiz, 2014: 247-258.

VELTRUSKÝ, Jiří. 1983. Puppetry and acting. Semiotica 47 (1983): 69-122.

VELTRUSKÝ, Jiří. 1990. Man and object in theatre. In Peter Steiner (ed.). The Prague School selected writings 1929-1946. Austin: University of Texas Press, 83-92.

WAGNER, Mieke. 2006. Other bodies: the intermedial gaze in theatre. In Freda Chapple and Chiel Kattenbelt (eds.). Intermediality in Theatre and Performance. Amsterdam: Rodopi Press, 2006: 125-136. 